\title{
Idosos residentes em uma instituição de longa permanência: adaptação à luz de Callista Roy
}

\author{
Elderly residents in homes for the aged: adjustment in the light of Callista Roy
}

Residentes mayores en un hogares para ancianos: adaptación a la luz de Callista Roy

\section{Maria Célia de Freitas', Maria Vilani Cavalcante Guedes', Francisca Tereza de Galiza', Jéssica de Menezes Nogueira', Marília Ribeiro Onofre'}

' Universidade Estadual do Ceará, Centro de Ciências da Saúde, Departamento de Enfermagem. Fortaleza-CE, Brasil.

\author{
Submissão: 07-02-2013 Aprovação: 23-09-2014
}

\section{RESUMO}

Objetivou-se avaliar o processo de adaptação de idosos que buscam, voluntariamente, residir em Instituição de Longa Permanência para Idosos (ILPI), na cidade de Fortaleza-CE, com base no modelo teórico de Roy. Pesquisa descritiva, realizada em uma IPLI com treze idosos residentes. A coleta de dados foi por meio de entrevista, nos meses de outubro e dezembro de 2011. Os dados foram tratados pela análise de conteúdo temática. Emergiram as seguintes temáticas: Eu Físico, subdividido em sensação corporal e imagem corporal; e Eu Pessoal, subdividido em auto coerência, auto ideal e ser moral-ético-espiritual. Assim, a opção de morar em ILPI não mudou efetivamente a vida dos idosos. Estes conseguiram adaptação ao local e convivem bem com os estímulos internos e externos.

Descritores: Cuidado; Enfermagem Geriátrica; Idoso; Adaptação; ILPI.

\section{ABSTRACT}

This study aimed to evaluate the adaptation of elderly individuals voluntarily reside in Institution for the Aged (LTCF) in the city of Fortaleza-CE, based on the theoretical model of Roy. Descriptive study, in a IPLI involving thirteen elderly residents. Data collect was through interviews in the months of October and December 2011 and organized by thematic content analysis. The following themes has emerged: I Physical subdivided into body sensation and body image; Staff and I, subdivided into selfconsistency and auto ideal be moral-ethical-spiritual. Thus, the option to live in ILPI not effectively changed the lives of elderly people. They managed to adapt to the local and coexist well with internal and external stimuli.

Key words: Caring; Geriatric Nursing; Elderly; Adaptation; Homes for the Aged.

\section{RESUMEN}

Este estudio tuvo como objetivo evaluar la adaptación de las personas mayores que residen voluntariamente en la Institución para la tercera edad (LTCF) en la ciudad de Fortaleza-CE, basado en el modelo teórico de Roy. Estudio descriptivo, en un IPLI con trece ancianos residentes. Los datos fueran recogidos a través de entrevistas en los meses de octubre y diciembre de 2011 y organizados mediante análisis de contenido temático. Emergieron los siguientes temas: subdivide I Física en la imagen corporal y sensación de cuerpo; El personal y yo, subdividen en auto-consistencia y auto ideal ser moral-ético-espiritual. Por lo tanto, la opción de vivir en ILPI no cambió de manera efectiva la vida de los ancianos. Se las arreglaron para adaptarse a lo local y convivir bien con los estímulos internos y externos.

Palabras clave: Cuidado; Enfermería Geriátrica; Anciano; Adaptación; Hogares para Ancianos. 


\section{INTRODUÇÃO}

O Brasil tem passado por um rápido e, relativamente, recente processo de transição demográfica e epidemiológica, no qual observamos uma expansão considerável do grupo etário acima dos 60 anos.

A população de idosos no país, entre 1999 e 2009, aumentou de 6,4 para 9,7 milhões. Em termos percentuais, a proporção subiu de $3,9 \%$ para $5,1 \%$. Em compensação, no mesmo período, caiu o número de crianças e adolescentes de $40,1 \%$ para $32,8 \%$, alargando o topo da pirâmide etária brasileira. Em decorrência desse aumento, a expectativa de vida do brasileiro atualmente é de 73,1 anos. As mulheres representam 55,8\% das pessoas com mais de 60 anos e a expectativa de vida feminina passou de 73,9 anos para 77 anos. Entre os homens, a expectativa de vida passou de 66,3 anos para 69,4 anos ${ }^{(1-2)}$.

No Estado do Ceará, o crescimento da população idosa segue os mesmos níveis nacionais, com os maiores de 60 anos tendo aumentado $61 \%$ em dez anos. Isso porque os dados do Censo 2010 confirmam que esse contingente etário está em 1,063 milhão de pessoas, enquanto em 2000 esse valor correspondia a exatos $658,9 \mathrm{mil}^{(1)}$.

Estudos sobre as consequências dessa transição mostram-se insuficientes, entretanto, já se pode vislumbrar modificações no perfil de morbimortalidade, com aumento da incidência de doenças crônicas não transmissíveis, bem como dos adoecimentos que levam as pessoas idosas à perda da capacidade funcional e, consecutivamente, a dependência total ${ }^{(3)}$.

Com o envelhecimento populacional, muitas questões sociais surgiram em diversos âmbitos, sendo um dos principais, a família, independente de como seja constituída. É nela que pode-se observar, dentre outras coisas, o surgimento de dificuldades no relacionamento com os idosos, em especial aqueles considerados dependentes por algumas condições de saúde, ocasionando desequilíbrio individual e coletivo ${ }^{(4)}$.

É neste contexto que as Instituições de Longa Permanência (ILPIs) assumem, cada vez mais, maior importância social, especialmente para os indivíduos de idade avançada e algum nível de dependência. As ILPIs constituem locais responsáveis pelo atendimento a idosos dependentes ou independentes. $\mathrm{O}$ atendimento é prestado a partir da verificação da inexistência de família, do abandono ou mediante carência de recursos financeiros do próprio idoso ou de sua família(5).

A probabilidade da admissão nessas instituições aumenta significativamente com a idade e grau de dependência. Com o boom da geração que envelhece, a demanda e os custos com estes serviços irão crescer decisivamente. Estima-se que $0,6 \%$ a $1,3 \%$ da população brasileira idosa se encontre em ILPIs ${ }^{(5-6)}$. Apesar das políticas priorizarem a família como responsável pelo cuidado ao idoso, a expectativa é de que aumente a demanda por ILPIs no Brasil, especialmente, porque alguns idosos, mesmo mantendo a independência e a autonomia, buscam espontaneamente esses locais para residir, geralmente por considerar sua participação familiar diminuída.

No entanto, o desenlace do vínculo familiar, ou mesmo a retirada de idosos que moram sozinhos no lar de origem, por certo necessitará de processo adaptativo na nova moradia, bem como na interação com os demais residentes, e ainda, com as pessoas que compõem a equipe de cuidado. $\mathrm{O}$ novo ambiente, certamente proporcionará estímulos diversos aos quais os idosos articularão estratégias de enfretamento e adequação, mantendo a integridade física e psíquica. Mediante o exposto, indaga-se: como ocorre a adaptação dos idosos que buscam, voluntariamente, a ILPIs para residir? Para fundamentar o estudo optou-se pelo modelo teórico de adaptação de Roy.

No modelo de adaptação, a pessoa surge como um ser adaptativo e holístico, receptor do cuidado prestado. É vista como um sistema, no qual as entradas são os estímulos, as saídas são respostas, utilizadas como retroalimentação, e os processos de controle conhecidos como mecanismos de enfrentamento ${ }^{(7-8)}$

Estes mecanismos são considerados formas de controle do sistema, com a finalidade de oferecer respostas aos estímulos existentes. Roy identificou quatro modos adaptativos ou categorias para a investigação de comportamentos que resultam dos mecanismos regulador e cognato. Os modos adaptativos são o fisiológico, o auto conceito, a função de papéis e a interdependência ${ }^{(7-8)}$.

Neste sentido, observando o comportamento dos idosos que residem por vontade própria nas ILPI, em relação aos modos adaptativos, a enfermeira poderá identificar as respostas adaptativas e as ineficientes nas diferentes condições apresentadas e planejar ações individualizadas, de forma a proporcionar acolhida, prevenindo alterações na saúde dos recém admitidos.

Para o estudo, optou-se pelo modo de autoconceito que se relaciona com a necessidade básica e de integridade psíquica. Seu enfoque está no aspecto psicológico e espiritual da pessoa, observando as subcategorias do ser físico e do ser pessoal. O ser físico tem componente de sensação e imagem corporais. O ser pessoal tem componentes próprios de auto coerência, de auto ideal e de ser moral-ético- espiritual. A sensação do corpo é como a pessoa apresenta o ser físico e a imagem do corpo é como a pessoa vê o seu físico. A auto coerência representa os esforços da pessoa para manter auto-organização e evitar o desequilíbrio. O autoconceito ideal representa o que a pessoa espera ser e fazer, e o ser moral-ético-espiritual representa o sistema de crenças e auto avaliação ${ }^{(7-8)}$.

O objetivo do estudo foi avaliar o processo de adaptação de idosos que buscaram, voluntariamente, residir em Instituição de Longa Permanência (ILPI) na cidade de Fortaleza-CE, alicerçado no Modelo de Adaptação de Roy, no modo autoconceito.

\section{MATERIAL E MÉTODO}

Pesquisa descritiva de natureza qualitativa, desenvolvida em uma instituição de longa permanência para idosos da cidade de Fortaleza-CE.

A população foi constituida por 213 idosos residentes no local, com idade igual ou superior a 60 anos. A amostra foi definida a partir da consulta de prontuários dos residentes 
admitidos voluntariamente. Foram identificados 25 idosos que atendiam aos critérios de autonomia e independência e exerciam as atividades básicas de vida diária (AVDs), como vestir-se, alimentar-se, tomar banho e as atividades instrumentais de vida diária (AIVDs), como fazer compras, tomar ônibus sozinho, organizar o local de moradia (dormitório).

A escolha de idosos independentes e autônomos deu-se devido à necessidade de perceber o nível de adaptação após a institucionalização em relação à manutenção da capacidade funcional com preservação da autonomia e da independência.

A coleta de dados foi realizada entre outubro e dezembro de 2011. As técnicas de produção de dados foram a entrevista semiestruturada e a observação com aplicação de um roteiro-guia, realizada em dias alternados com as entrevistas, de modo que se pudesse observar a convivência e a interação dos idosos no local. Para complementar as falas dos idosos, era registrados no diário de campo as expressões faciais, as posturas manuais, bem como os momentos de silêncio.

Durante todo o desenvolvimento do estudo foram observados os preceitos éticos e legais das pesquisas envolvendo seres humanos. O projeto foi apreciado pelo Comitê de Ética em Pesquisa da Universidade Estadual do Ceará, processo nº. 100297668; FR- 331757 de 05 de janeiro de 2011. A Coordenadora da Instituição de Longa Permanência para Idosos (ILPI) também aprovou e autorizou a sua realização e indicou o local apropriado para as entrevistas.

Os idosos foram convidados e receberam informações sobre a pesquisa e aqueles que, após os esclarecimentos, concordaram em participar, foram orientados quanto à assinatura do Termo de Consentimento Livre e Esclarecido. Comunicamos, também, que mesmo tendo concordado em participar poderiam retirar o consentimento em qualquer etapa da investigação, sem qualquer prejuízo.

Os dados foram tratados por meio de análise de conteúdo temática ${ }^{(9)}$, que identifica temas que são unidade de significação inspirado no modelo teórico de Roy, representando elementos significativos do processo de adaptação dos idosos institucionalizados.

As temáticas foram definidas a partir dos indicadores de adaptação das subcategorias do modo do autoconceito do Modelo de Adaptação de Roy, a saber: Eu Físico, subdividido nas temáticas Sensação Corporal e Imagem Corporal; e Eu Pessoal, subdividido nas temáticas auto coerência, auto ideal e ser moral-ético-espiritual.

\section{RESULTADOS E DISCUSSÕES}

Os sujeitos do estudo eram na maioria, do sexo masculino19 (76\%), a idade variou de 60 aos 80 anos, com média de 71,2 anos. O tempo de residência no local variou de dois a três anos, sendo as mulheres com maior tempo de moradia, três anos. Todos os entrevistados possuíam alguma ocupação que exerciam voluntariamente e que passaram a não exercê-la após a institucionalização. A fonte de renda era a aposentadoria, que variava de dois a três salários mínimos, calculado sobre o salário vigente à época da pesquisa, de R\$622,00 (seiscentos e vinte e dois reais). Dentre os idosos residentes e participantes do estudo, exceto as mulheres, 6 (24\%) todos saíam para visitar amigos ou familiares, retornando à instituição somente à tarde.

Dessa forma, para compreender como os idosos se adaptavam à instituição, foram observados os aspectos que poderiam apresentar relações com o fato, compreendendo o Modelo de Roy que descreve a pessoa como um ser adaptativo, capaz de se adequar não só de forma emocional à situação, mas também às novas necessidades que a sua nova condição exige $\mathrm{e}^{(7-8)}$. Entende-se que a adaptação é um processo e resultado por meio dos quais as pessoas utilizam a consciência e a escolha para criar a integração e a adaptação humana e ambiental.

No caso dos idosos que procuraram as ILPIs para residir, os estímulos interiores e os exteriores evidenciavam o elemento do ambiente que representa todas as condições, circunstâncias e influências que circundam e afetam o desenvolvimento e o comportamento dessa pessoa. Os idosos que optaram por um novo local de moradia rompem anos de convivência com os familiares, a partir de estímulos ambientais externos que agiram sobre eles. Para realizar os enfrentamentos e ter adaptação positiva às mudanças, os idosos justificam as decisões pelas perdas físicas decorrente do processo de envelhecimento, pelo Eu Físico.

\section{O Eu Físico - sensação e imagem corporal}

No relato da maioria dos idosos, a velhice revela-se marcada pela desvalorização da vida, especialmente, pelas perdas. A lembrança da juventude livre, plena de força, mostra-se como algo bom de ser recordado, um possível retorno desejado. As expressões observadas denotavam tristeza, marcadas por olhares vagos, expressões desordenadas das mãos, principalmente, nos momentos em que se permitiam recordar aspectos do passado.

Eles afirmam que a velhice traz muitas mudanças, perdas, culminando com dificuldades. Eem decorrência disso, decidem afastar-se da família por não se considerar mais produtivo e ser um peso em casa. Muitas vezes, incorporam certos estereótipos relacionados ao envelhecimento. Por isso, muitos retratam certos comportamentos não adaptativos que podem ser evidenciados, especificamente, em relação à temática da Sensação Corporal:

[...] eu me sinto fraco [...] não tenho aquela força toda não [...] quando jovem sim, eu tinha vigor, andava e passeava muito, tempos que não podemos fazer voltar [...] meu corpo não aguenta muito esforço, deve ser a idade que aumenta a cada ano e deixa a gente muito cansada. Eu vim morar aqui, eu gosto, estou me acostumando. O motivo de minha decisão [...] não queria atrapalhar meus filhos. Eles não têm tempo de olhar para mim, eu estava sendo um peso, um peso morto, aquele que todos têm que carregar, mesmo que não queira. (E1)

Pelas falas dos participantes fica evidente que a sua percepção em relação ao eu físico, Ihe atribui um significado de fraqueza, dependência e desinteresse da família. Este significado pode estar relacionado às experiências no decorrer da vida, às 
atividades e ao domínio que tinham na família, quando suas vontades eram atendidas e obedecidas pelos filhos. Justificam as condições físicas alteradas como motivo do distanciamento e escolha por residir na ILPI.

Sabe-se que com o envelhecimento pode haver prejuízo na funcionalidade das pessoas que é compreendida como a capacidade de realizar atividades de vida diária, relacionadas ao autocuidado, e as atividades instrumentais de vida diária, como gerenciar a moradia, com autonomia e independência. As pessoas buscam outro local como artifício de mudança e retomada de suas decisões. No entanto, a mudança e os contínuos estímulos do cotidiano, na nova moradia, podem provocar desinteresse e a ineficácia na adaptação dos idosos ${ }^{(10)}$.

As experiências da vida ocorrem por meio do corpo. É com este e por meio deste, que se vivencia a experiência. Assim, o corpo tem relação direta com o mundo, é o ponto de vista, referência das pessoas e para elas e para os outros. É o meio onde o sujeito se reconhece, campo de todos os pensamentos e percepções, por isso, antes de qualquer análise que se possa fazer dele, deve-se observar como a pessoa o considera e como viabiliza os seus potenciais ${ }^{(11)}$. Sabe-se que a velhice pode desencadear alguma dependência física, que os impede de realizar atividades da vida cotidiana, especialmente, de trabalho e comando familiar, sendo esta temida pelos idosos ${ }^{(6)}$.

Além disso, a Sensação Corporal também engloba outros componentes como o bem estar sexual, que se traduz pelo sentimento e pela experiência do bem estar físico chamado por Roy de Função sexual efetiva ${ }^{(7-8)}$. Este aspecto também foi referido nas falas dos participantes:

Quando eu saio, eu vou pra casa da minha namorada, que gosta de mim [...] Ela me trata bem e, de vez em quando, eu durmo por lá mesmo [risos], não precisa retornar prá cá. Nos damos muito bem, ela pensa em vir morar aqui para ficar comigo, mas a filha não quer. (E2)

[...] eu não preciso permanecer todo tempo aqui, eu saio, vou à casa dos filhos e filhas [...] outro dia arrumei uma namorada, na mesma rua que eu morava. Eu não percebia ela, precisei sair para observar aquela mulher tão boa [...] então, nós, ainda estamos namorando, mais um motivo pra eu me sentir inteiro. (E25)

Percebe-se que é necessário estimular o direito à privacidade e intimidade, favorecer o convívio, o namoro e as trocas afetivas entre idosos. A garantia disto possibilita a eles exercerem, pelo menos neste aspecto, atividades que meIhor facilitariam sua adaptação na instituição, sendo ela estimulante neste processo e mesmo um caminho para eles se completarem $^{(12-13)}$

Outros idosos, a partir de seus relatos, demonstram baixo nível de satisfação com a própria aparência, fato que caracteriza uma resposta inefetiva em relação à temática da Imagem Corporal:

Gostar? Eu não. Tenho muito tempo aqui, mas não me acostumo. Não dá para gostar de muita coisa não [...] De mim? o que é que eu vou gostar em mim se eu já sou veIho? Diga-me, o que posso gostar em mim? ninguém nem olha para mim, minha filha [...] então o que posso dizer? Antes quando jovem, sim, aí sim, eu me achava linda, tinha muitos admiradores. Hoje, nem me olho no espelho para não enxergar a velhice. (E17)

As funcionárias e enfermeiras sempre falam que sou linda, mas não acredito, nisso, imagina, sou muito velha. Assim, decidi morar aqui, longe dos muitos jovens que moram em minha casa, não dava para conviver. Eu gosto de silêncio, eles gostam de muito barulho, não tinha condições. (E3)

[...] se gosto de mim? Claro que gosto, mas do meu corpo, agora não [...] estou tão velho, não sou mais bonito, passou ... fui um dia muito forte, mas agora, estou velho ... dou apenas para o gasto ... As garotas falam que ainda sou bonito, mas não acredito, o que acha? (E21)

O corpo envelhecido é medido, para essas pessoas, por determinadas características físicas e modificações no seu estilo de vida, além da idade cronológica. As representações sobre o corpo falam de perda gradativa da força, da potência, da beleza e da independência, acompanhadas pela imagem de incapacidade ${ }^{(11)}$. Durante a entrevista, quando solicitados para pensar e refletir sobre os bons acontecimentos na família, para identificar o que mais contribuiu para a decisão de morar na ILPIs, eles respondem:

Morar aqui, longe da minha família, não é bom, mas eu não tenho minha velhinha, posso ficar aqui, ninguém sente a menor falta, mesmo que eu não desse trabalho a eles [...] perdi meu posto de chefe de família [...]. (E14)

Meus filhos diziam que ficavam preocupados quando eu saía de casa, tinham medo que eu passasse mal. Quando decidi morar aqui, eles nem lamentaram [...] menos uma responsabilidade para eles. É, minha filha, a velhice leva a isso, você já imaginou? (E18)

A construção da imagem sobre a velhice não tem uma relação de unicidade com o processo físico de envelhecimento mas, principalmente, com o contexto econômico e social. Por isso, afirma-se que a velhice seja uma construção social, não sendo apenas uma manifestação da subjetividade, isto é, de sentir-se velho, mas uma realidade biológica que se relaciona de forma profunda com o contexto social e histórico ${ }^{(12)}$. Nessa perspectiva, a associação de velhice com doença resulta de um processo de produção social que, em última análise, guarda estreita relação com a perda da juventude e de sua força característica, bem como com as perdas no ambiente familiar. Os idosos sempre afirmam dificuldades no convívio com os mais novos e, assim, buscam distanciar-se com o intuído de não causar desarmonia entre os filhos ${ }^{(13)}$.

A admissão do idoso na ILPI faz com que ele perca, muitas vezes, os objetos particulares e simbólicos: elo de ligação entre sua história e seu eu. $\mathrm{O}$ ambiente onde está inserido inibe e distorce as reservas de informações particulares, ocorrendo 
ou não, a perda da intimidade, processo esse desencadeado pela institucionalização. O cuidado com a pessoa idosa depende de uma rede ampla de assistência, porém, em muitas situações, a escassez dessa assistência leva a pessoa a ser encaminhada para as ILPI ${ }^{(14)}$.

Percebe-se, portanto, que a utilização do modelo de adaptação de Roy permite reconhecer que os idosos, mediante estímulos, podem desencadear respostas, ora positivas ora negativas, em situações estressantes, cabendo ao enfermeiro atuar como mediador entre a objetividade técnica e a subjetividade humana, elaborando estratégias para as ações de cuidado cotidiano, a partir do entendimento da história de cada um. Poder capacitar os idosos para criar mecanismos de enfrentamento que possam diminuir as respostas negativas, favorecendo sua vivência e facilitando a interação com os demais residentes. ${ }^{(12)}$

Considera-se que os dados obtidos poderão fornecer elementos de reflexão para a equipe de enfermagem das ILPIs, quanto ao valor das relações interpessoais, tido como principal recurso para o atendimento das necessidades em todas as situações, reconhecendo que todos buscaram o local, porém preservam intimamente a vontade de retornar para o convívio dos filhos e amigos.

Revelou-se, ainda, nas falas que o eu físico é um dos fatores que impulsiona o idoso a buscar a instituição. Eles consideram que a velhice traz como consequência, múltiplas preocupações e trabalho para seus familiares e, por não desejar ser estorvo, decidem que o melhor local são as ILPIs. Mesmo que no local eles tenham toda a liberdade de deslocamento, sentem falta do lar e do convívio com as pessoas.

\section{O Eu Pessoal - auto coerência, auto ideal e ser moral-ético-espiritual}

A temática Eu Pessoal refere-se à pessoa, sendo subdividida em auto coerência, auto ideal e ser moral-ético-espiritual. A auto coerência diz respeito aos esforços da pessoa para manter a auto- organização e evitar o desequilíbrio(6).

Assim como pessoas de diferentes idades têm necessidades de variados tipos, o idoso também precisa continuar crescendo. Isso deve ser traduzido em como continuar aprendendo. É certo que a capacidade de aprender na idade mais avançada não é a mesma que na juventude, mas é preciso aceitar a ideia de que os idosos continuam aprendendo de outra forma, com outro ritmo, com outros interesses ${ }^{(13)}$.

Para muitos idosos, a internação em uma ILPI caracteriza-se como um processo de isolamento social, em que boa parte do que foi construído na vida adulta permanece apenas no passado, na memória. A instituição, que deveria ser a mantenedora dos costumes dos seus residentes, muitas vezes, não garante esta continuidade, provocando uma ruptura dos seus referenciais individuais. A percepção desta quebra pode transformar-se em uma situação difícil para lidar, que muitos inicialmente não suportam:

[...] quando eu cheguei aqui, até que eu tentei ser forte. Na verdade, eu sou uma pessoa forte ... Mas quando eu me lembrava das minhas coisinhas, da minha casa, eu chorava. Me dá um nó na garganta, não tem como não sentir, foi uma vida inteira, para num minuto abandonar tud, eu ainda sofro, mesmo saindo todos os dias. (E5)

Muitas vezes, apesar dos esforços dispensados a fim de garantir o equilíbrio em certas situações, os idosos afirmam que não se adaptaram ao novo ou apresentam dificuldades para a adaptação ao novo, Ou seja, mesmo que tenham articulado estratégias de enfrentamento, estas não foram satisfatórias, o que demonstra a inefetividade de uma resposta. $\mathrm{O}$ entendimento dessa condição ajuda o enfermeiro a promover a adaptação a essa mudança ou a adotar intervenções que minimizem as alterações e os comportamentos não efetivos, promovendo respostas adaptativas.

Questionados a respeito da existência de planos para o futuro, os relatos constituíram dois grupos distintos. Somente cinco dos participantes relataram não possuir plano de retornar ao convívio da família. Os 20 outros almejavam sair da instituição e voltar a morar com novos parceiros encontrados na instituição ou fora dela.

Para as mulheres, a instituição torna-se um local definitivo, ao qual devem se adaptar. Mas, para os homens, esta é vista como temporária, fruto da necessidade de melhoria na condição financeira, do estado de saúde ou mesmo da solidão, o que pode ser resolvido no período de institucionalização ${ }^{(15)}$.

Cinco idosas, dentre as seis entrevistadas, expressaram resignadamente nas suas falas não desejar retornar para a família:

Tenho não, minha filha! Não tenho mais vontade de sair. Eu já nem ligo pra isso. Eu só sei que quando eu não puder fazer mais nada, quando eu já estiver bem velha, vão me levar pra o salão e eu vou esperar minha morte ... Eu sei que vai ser assim, fazer o que? Meus filhos estão casados e não podem cuidar de mim, têm mulher e filhos, estão ocupados, quando decidi morar aqui, decidi mesmo, não olhei e nem olho para trás. (E22)

Tenho fé em Deus que não me arrependo, aceito minha sina. Vi isso quando perdi meu marido. Então quem cuida de mim, são somente as pessoas daqui. Estou conformada, não vou mais voltar para minha casa, é triste, mas não quero mais voltar, não tem mais sentido. (E8 e13)

Apesar dos relatos das idosas de pretender não deixar a instituição, os demais entrevistados demonstraram interesse em sair, a fim de construir outra família a partir de novos relacionamentos ou restabelecer vínculos afetivos com os parentes ainda próximos ou com amigos ainda existentes. Percebeu-se coerência representada pelo esforço em retomar a organização e o equilíbrio da vida e o ideal refletido pelo querer ser e fazer na construção de uma nova vida:

Eu quero sair daqui, em janeiro, março no mais tardar [...] eu quero mesmo é viajar pro meu interior pra visitar meu pai. Não posso cuidar dele, mas quero ficar perto dele, no interior. Ali é o meu lugar, tenho fé que logo sairei, foi um momento que dei à minha filha para descansar das minhas 
coisas. Não quero mais morar com ela, quero refazer minha vida, ainda, estou inteiro, de pé, posso fazer muitas coisas [...]. (E9 e 12)

[...] estou planejando minha saída para ficar com minha nova companheira. Ela não quer morar aqui. Ela me entende muito bem, temos a mesma idade, mas não posso trazer ela para cá, não temos muita privacidade. Não reclamo das coisas daqui, mas quero morar sozinho com ela. Não quero voltar para casa de meus filhos [...] era o mesmo que morar sozinho, eu tinha um pouco de medo e solidão, era eu e Deus [...]. (E16)

De acordo com os relatos, pode-se verificar que alguns idosos, apesar de garantirem a internação por vontade própria, demonstram desejo de morar em outro local, ausentando-se da instituição, não desejando que esta seja sua última morada.

A dinâmica familiar foi interpretada como razão para os idosos não terem companhia familiar para morar com eles. Com relação à família, o falecimento do cônjuge e de outros familiares, os desentendimentos e as decisões que excluíram o idoso do convívio com a família, contribuíram para ir morar na ILPI, motivo também identificado em estudo realizado em Curitiba, Paraná(16).

Ainda, considerando o ser pessoa, concernente ao ser moral-ético-espiritual, definido como o sistema de crenças e auto avaliação, foram analisados aspectos das crenças espirituais dos idosos, como eles se vêem, de acordo com seu sistema de valores.

Nas falas ficou claro que todos os idosos tinham crenças e hábitos religiosos efetivos, observado pela frequência às atividades da capela existente na instituição. A religiosidade e a fé foram temas abordados e relevantes nas falas:

Vou à missa sempre. Falto apenas quando tenho algum problema de saúde, quando estou impossibilitado de me levantar. Principalmente aos domingos. Eu gosto de ir para orar pros meus filhos. Mas eu rezo pra mim também, peço a Deus para nunca me arrepender de morar aqui, as pessoas são boas [...]. (E6)

A vida tá muito difícil, todos os dias rezo sozinha pedindo ajuda para suportar a ausência dos meus filhos, sei que eles sofrem com a minha decisão de vir morar aqui, quando eles melhorarem de dinheiro, então eu posso voltar, quem sabe é Deus [...]. (E11)

[...] antes de vir para cá, eu não ia muito à missa, hoje vou sempre que posso [...] gosto, me deixa mais tranquilo, para ficar aqui e pensar em quando retornar, fazer meus planos. Quero que meus filhos fiquem bem, [...] eles trabalham muito, tenho seis; dois homens e quatro mulheres. Quando a minha velha morreu, decidi morar aqui. Pago todas as minhas despesas [...] não quero dar trabalho a eles. Eles não param em casa, têm filhos e não podem ficar comigo. Quando desejo, vou em casa [...], mas penso que não quero mais morar com eles, quero voltar para o interior.
Conheci uma pessoa que me apoia, não estarei sozinho, é muito ruim a solidão. Aqui tem muita gente boa, mas não é a casa da gente. (E7e 10)

Os idosos relataram que não queriam ficar sozinhos em casa e diferentes razões foram apontadas para isso, como medo de assaltante, falta de companhia e porque não teria alguém para os socorrer na ocorr6encia de algum problema. A última justificativa está relacionada à consciência dos problemas de saúde e à insegurança que sentem devido a isso.

Diante das diferentes situações dos idosos e suas perdas, as alterações do processo de envelhecimento, o medo de ser obstáculo na vida dos filhos, eles decidiram viver em uma ILPI. Eles interpretaram a escolha como necessária para a manutenção da sua saúde e bem-estar, que estava ameaçada pelo isolamento social. Quanto aos familiares, afastaram a culpa pela ausência e não atenção contínua. Morar na ILPI significou buscar proteção, amparo, segurança, convivência e fortalecer laços sociais com as outras pessoas, além da família(13). Essa escolha, entretanto, está permeada por aspectos sociais, culturais e familiares, bem como suas histórias de vida, revelado pelo autoconceito de cada um, outra justificativa para a escolha do resgate da valorização do idoso como ser de autonomia e independência, na tomada de decisões, nas escolhas.

O autoconceito de um indivíduo é definido por Roy como composto por crenças ou sentimentos que ele possui sobre si próprio num dado momento ${ }^{(7-8)}$. A crença dos idosos em meIhores dias, em encontrar acolhida, os fortalece, especialmente, quando decidem deixar o convívio familiar para residirem em outro local. Isto os fortalece, uma vez que necessitam buscar estratégias de enfrentamento para se adaptar ao novo ambiente e a todos que compõem o local.

Nos idosos, a religiosidade assume papel importante como estratégia efetiva de fortalecimento. A religião ajuda-os a enfrentar situações difíceis, perdas, amenizando os acontecimentos negativos, ressignificando-os em suas vidas.

$\mathrm{O}$ atributo de pessoas religiosas esteve presente e foi entendido como uma forma particular de olhar a vida e construir o mundo a partir de concepções simbólicas transmitidas de geração a geração. A religião serve tanto para a formulação das concepções gerais do mundo, de si e das relações entre elas, como também influencia os comportamentos e as experiências humanas ${ }^{(17)}$.

O significado atribuído à vivência na ILPI apareceu como um fator que influencia os sentimentos dos idosos e está relacionado à autonomia na decisão de ir viver em uma ILPI. Embora, todos atribuíssem a escolha motivada pelas impossibilidades causadas pela velhice, o medo da dependência dos filhos e as ausências das pessoas de casa, contribuíram para a decisão dos idosos. Esse evento denota o poder da autonomia e independência nas decisões ${ }^{(17)}$.

Para os idosos, a família possui papel relevante no seu suporte social. Entretanto, as falas evidenciaram que nem todas as famílias tomam para si tal responsabilidade, ausentando-se, muitas vezes, do cuidado. Foi através desta ausência que os idosos passaram a se sentir solitários dificultando a adaptação às mudanças, mesmo com os esforços de cada um. 
As respostas de adaptação são as que promovem a integridade e ajudam os idosos a atingir os objetivos de adaptação, isto é, sobrevivência, crescimento, reprodução e transformação da pessoa e do ambiente, representadas por meio das expectativas da maioria dos idosos. Vinte deles (80\%) projetarem um futuro fora da ILPI com outras parceiras. No entanto, nas falas, percebem-se respostas ineficazes que ameaçam os objetivos de adaptação.

A partir do conhecimento das respostas dos idosos, a Enfermagem deve ajudar neste processo de adaptação, gerindo os estímulos externos ambientais. O resultado poderá ser a obtenção de um nível ótimo de bem-estar por parte da pessoa. As estratégias de desenvolvimento das relações sociais são facilitadoras para o desenvolvimento de comportamentos adaptativos às situações estressoras, durante a vida dos idosos da sociedade e institucionalizados.

\section{CONSIDERAÇÕES FINAIS}

O estudo revelou que os idosos justificam sua escolha de morar em ILPI tanto pelo eu físico, expressando as dificuldades impostas pelas alterações da velhice e, ainda, o eu pessoa quando mencionam a religião como fortalecedora das respostas eficazes, o auto ideal quando apresentam novos projetos de vida e auto coerência na exposição de auto-organização, evitando o desequilíbrio e apontando novos caminhos.

Em alguns casos, revelaram a adaptação ineficaz, mesmo sendo uma decisão espontânea. Porém, a quebra dos laços familiares, ocasionado pelo distanciamento da convivência, é sentida e revelada quando buscam o fortalecimento pela religião. Outros conseguem adaptar-se ao local, pois estão num contínuo ir e vir de aproximação com os amigos e familiares. Assim, a opção de morar em ILPI não mudou efetivamente suas vidas, conseguindo adaptar-se ao local e conviver bem com estímulos internos e externos, igualmente significativos.

Mesmo considerando que os idosos apresentaram comportamentos adaptativos ao local escolhido, observou-se, também, tendência para buscar novos caminhos que possibilitem melhor satisfação, possivelmente como tentativa de substituir a ausência deixada pela família. Revelam o não desejo de retornar ao ciclo familiar para garantir a independência e a autonomia perdidas, fatos estes observados nas falas de desejo de construção de um novo convívio com parceiras conhecidas no local ou fora dele.

Para os enfermeiros, conhecer os estímulos ambientais externos significativos que são impostos aos idosos quando deixam seus familiares e escolhem viver em ILPI, os ajuda a promover a adaptação a essa mudança, planejando intervenções que minimizem o risco da não adaptação, controlando os estímulos focais, contextuais ou residuais impingidos sobre os idosos. Fazendo ajustes, os estímulos poderão facilitar o processo de adaptação dos idosos.

As limitações do estudo se deram porque foi trabalhado apenas o modo autoconceito e não os quatro modos, visto que permitiam discutir e viabilizar melhores estratégias de enfretamento de adaptação dos idosos pela análise do modo fisiológico, função de papéis e interdependência.

\section{REFERÊECIAS}

1. Instituto Brasileiro de Geografia e Estatística (BR). Resultados do Censo 2010 [Internet]. [S.I]: IBGE; 2010 [acesso em 18 de novembro de 2012]. Disponível em: http://censo2010.ibge.gov.br/resultados

2. Instituto Brasileiro de Geografia e Estatística (BR). IBGE: população brasileira envelhece em ritmo acelerado [Internet]. [S.I]: IBGE; 2006 [acesso em 13 de novembro de 2011]. Disponível em: http://saladeimprensa.ibge. gov. br/noticias? view $=$ noticia\&id $=1$ \&busca $=1$ \&idnotic $\mathrm{ia}=1272$

3. Chaimowicz F, Camargos MCS. Envelhecimento e saúde no Brasil. In: Freitas EV, Py L, Cançado FAX, Doll J, Gorzoni ML. Tratado de Geriatria e Gerontologia. 3. ed. Rio de Janeiro: Guanabara Koogan; 2011. p.74-96.

4. Varoto VAG, Truzzl, OMS,Pavarini, SCl. Programas para idosos independentes: um estudo sobre seus egressos e a prevalência de doenças crônicas. Texto \& Contexto Enferm [Internet]. 2004 [acesso em 18 de novembro de 2012];13(1);107-14. Disponível em: http://www.redalyc. org/articulo.oa? id $=71413115$

5. Menezes RL, Bachion MM, Souza JT, Nakatani AYK. Estudo longitudinal dos aspectos multidimensionais da saúde de idosos institucionalizados. Rev Bras Geriatr Gerontol [Internet]. 2011 [acesso em 18 de novembro de 2012];14(3):485-96. Disponível em: http://www.scielo. br/pdf/rbgg/v14n3/v14n3a09
6. Creutzberg M, Gonçalves LHT, Sobottka EA, Ojeda BS. Long-term care institutions for elders and the health system. Rev Latinoam Enferm. 2007;15(6):1144-9.

7. George JB. Nursing theories: the base for professional nursing practice. $6^{\text {th }}$ ed. New Jersey: Pearson Education; 2010.

8. Roy SC. The Roy Adaptation Model. $3^{\text {th }}$. ed. London: Person Education LTD; 2009.

9. Bardin L. Analise de Conteúdo. 7. ed. Lisboa: Editora 70; 2010.

10. Santos ACSS, Santo FHE, Pestana L, Daher DV, Santana R. Insuficiência cardíaca: estratégias usadas por idosos na busca da qualidade de vida. Rev Bras Enferm. 2011;64(5):857-63.

11. Fernandes MGM, Garcia LG. O corpo envelhecido na percepção de homens idosos. Rev Bras Enferm. 2011;64(3):472-7.

12. Silva ACS, Santos I. Promoção do autocuidado de idosos para envelhecer saudável aplicação da teoria de Nola Pender. Texto \& Contexto Enferm [Internet]. 2010 [acesso em 18 de novembro de 2012];19(4):745-53. Disponível em: http://www.scielo.br/scielo.php?pid=S0104$-07072010000400018 \&$ script $=$ sci_arttext

13. Freitas MC, Oliveira MF. Assistência de enfermagem ao idoso que realizam cateterismo cardíaco: uma proposta a 
partir do modelo de adaptação de Callista Roy. Rev Bras Enferm. 2006;59(5):642-6.

14. Cruz RC, Ferreira MA. Um certo jeito de ser velho: representações sociais da velhice por familiares de idosos. Texto \& Contexto Enferm [Internet]. 2011 [acesso em 18 de novembro de 2012];20(1):144-51. Disponível em: http://www.scielo.br/scielo.php?script=sci_arttext\&pid $=$ S0104-07072011000100017

15. Salomão GSM, Azevedo RCS. Os fios visível e invisível da experiência do exame físico para o cliente. Texto \& Contexto Enferm [Internet]. 2010 [acesso em 18 de novembro de 2012];19(4):675-81. Disponível em: http://www.scielo.br/ scielo.php?pid $=$ S0104-07072010000400010\&script =sci_arttext

16. Michel T, Lenardt MH, Betiolli SE, Neu DKM. Meaning assigned by the elderly to the experience at a long stay institution: contributions for the nursing care. Texto \& Contexto Enferm [Internet]. 2012 [cited 2012 November 18];21(3):495-504. Available from: http://www.scielo.br/ scielo.php?pid = S0104-07072012000300002\&script $=$ sci arttext\&tlng $=$ en

17. Vitorino LM, Viana LAC, Paskulin LMG. Quality of life among older adults resident in long-stay care facilities. Rev Latinoam Enferm. 2012;20(6):1186-95. 